\title{
Mimosa dasilvae, UMA NOVA MIMOSACEAE DA AMAZÔNIA BRASILEIRA
}

\author{
Antônio Sérgio L. da SILVA', Ricardo de S. SECCO'
}

RESUMO - Uma nova espécie de Mimosaceae para a Amazònia Brasileira, denominada Mimosa dasilvae A. S. Silva \& R. Secco, é descrita e ilustrada. O novo táxon pertence à secção Habbasia sér. Piresianae Barneby e apresenta afinidades com M. piresii Barneby, da qual difere, principalmente, pelo hábito lianescente, foliólulos menores, glabros e brilhantes na face ventral, e brácteas florais menores.

Palavras-chave: Mimosaceae, Mimosa, Taxonomia.

\section{A New Species of Mimosaceae from Brazilian Amazon, Mimosa dasilvare}

ABSTRACT - A new species of Mimosaceae from Brazilian Amazon, called Mimosa dasilvae A. S. Silva \& R. Secco is described and illustrated. The new taxon belongs to sect. Habbasia ser. Piresianae and shows affinities with $M$. piresii Barneby, from which differs specially in long, liana-like habit, smaller, ventrally glabrous and lustrous leaflets, and very small floral bracts.

Key-words: Mimosaceae, Mimosa, Taxonomy.

\section{INTRODUÇÃO}

Mimosa L. é um gênero com 479 espécies e 225 táxons infraespecíficos, perfazendo um total de 704 táxons (Barneby, 1991), distribuídos, predominantemente, nas Américas Central e do Sul, estendendo-se muito pouco até a África e Ásia (Lewis \& Elias, 1981).

Em um trabalho de atualização das identificações das Mimosaceae do herbário do Museu Goeldi, o gênero vem sendo estudado pelo autor principal. No material analisado, encontrou-se uma coleção de Mimosa que diferia das demais coleções procedentes do Estado do Pará, o que levou a suspeitar-se que tratava-se de um novo táxon para o gênero.

Consultando-se o Dr. Rupert Barneby, uma das maiores autoridades na família Leguminosae, obteve-se a confirmação de que tratava-se realmente de uma nova espécie para o gênero.

\section{DESCRIÇÃO DA ESPÉCIE}

Mimosa dasilvae A. S. Silva \& R. Secco, sp. nov. Tipo: Brasil. Pará, municipio de São Félix do Xingu, serra de Campo, nov. 1995 (fl), J. B. da Silva 501 (holótipo, MG). (Figs. 1-14).

Specie affini $M$. piresii Barneby, sed differente ex ea ut liana, foliolis minoribus, ventraliter glabris nitentibusque, stipulis minoribus, lanceolatis setosisque, trichomatibus calicis attingentibus supra medietatem corollae, sed etiam bracteis floralibus minoribus.

Liana prostrada com mais de 10 m de comprimento. Ramos estrigosopilosos, angulosos; estípulas triangulares, papiloso-setosas no dorso, glabras na face ventral, $9 \mathrm{~mm}$ de comprimento, 0,6 $\mathrm{mm}$ de largura, persistentes. Peciolo 3-4 cm de comprimento, anguloso; pinas 6-9 jugas, segmentos entre as pinas $1,5-2,5$ 
$\mathrm{cm}$ de comprimento; raque arqueada, apêndice terminal lanceolado, 4-5 mm de comprimento; foliólulos 7-11 pares; lâminas obliquamente ovais, base cordada, ápice obtuso, mucronado, mucron com até $1 \mathrm{~mm}$ de comprimento, brilhantes na face adaxial e opacas na abaxial. Foliólulos apicais com 1,5-2 cm de comprimento, 0,5-0,9 $\mathrm{mm}$ de largura, os basais $1,3 \mathrm{~cm}$ de comprimento, 0,4 $\mathrm{mm}$ de largura; face abaxial estrigosopilosa, tricomas esparsos sobre a lâmina, mais concentrados na nervura central; face adaxial glabra, estrigosopilosa apenas no terço inferior da nervura central; nervuras secundárias 2, apenas no lado maior do foliólulo, proeminentes na face abaxial, promínulas na adaxial, foliólulos brilhantes na face adaxial, opacos na abaxial. Inflorescência em panícula terminal, ca. $35 \mathrm{~mm}$ de comprimento, raque estrigoso-pilosa; pedúnculos 23 por nó, raramente solitários, 1,9-2,1 $\mathrm{cm}$ de compimento., estrigosos; bracteolados logo abaixo do capitulo; bractéolas espatuladas, ou linearlanceoladas, $5-9 \mathrm{~cm}$ de comprimento, 0,5-1 $\mathrm{mm}$ de largura, estrigosas. Capitulo globoso ou cônico na préântese. Flores tetrâmeras, a maioria bissexual; cálice paleáceo-papiforme, tubo $0,2-0,3 \mathrm{~mm}$ de comprimento, ápice setoso com cerdas longas, atingindo até a metade do tubo da corola; corola tubulosa $2,5-4 \mathrm{~mm}$ de comprimento, tubo da corola glabro, os lobos setosos externamente, glabros internamente; estames 8 , filetes corde-rosa, levemente concrescidos próximo à base do ovário, exsertos, 1 -
$1,8 \mathrm{~cm}$ de comprimento; ovário menos de $1 \mathrm{~mm}$ de comprimento, glabro, estilete curto, lateral. Frutos não vistos

Mimosa dasilvae pode ser incluída na secção Habbasia sér. Piresianae Barneby, especialmente por apresentar estípulas subfoliáceas, sem nervuras evidentes externamente, inflorescência em panícula robusta e cálice paleáceo-papiforme. Trata-se de uma espécie afim de Mimosa piresii Barneby (Pires 16067, isótipo MG), diferenciando-se desta pelo hábito lianescente, foliólulos menores, ventralmente glabros e brilhantes, tricomas do cálice abaixo da metade da corola, estípulas triangulares papilosas, e pelas brácteas florais menores. Mimosa piresii distingue-se de Mimosa dasilvae por ser um arbusto com foliólulos maiores, ventralmente estrigosos e opacos, estipulas menores, lanceoladas, setosas, tricomas do cálice atingindo além da metade da corola e as brácteas florais maiores.

Mimosa dasilvae é uma espécie com potencial ornamental e cresce no campo rupestre aberto, entre rochas do tipo canga, em altitude de $600 \mathrm{~m}$.

O epíteto específico é uma homenagem ao coletor da espécie, o botânico prático João Batista Fernandes da Silva, pelo dedicado programa de coleta e estudos que vem realizando nos mais longínquos ecossistemas da Amazônia.

\section{AGRADECIMENTOS}

Ao Dr. Rupert Barneby, do New York Botanical Garden, pela orientação dada a este trabalho; ao 


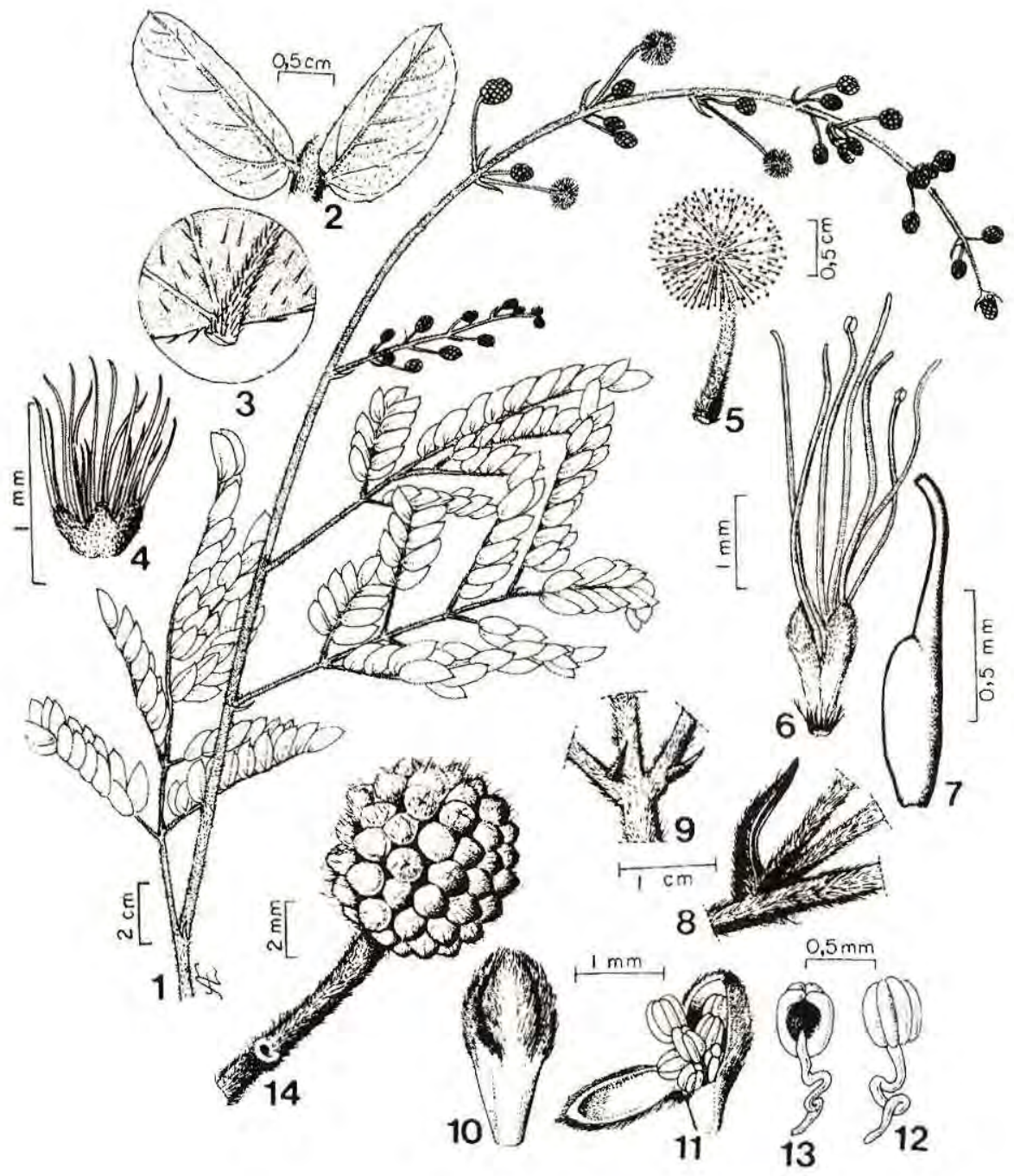

Figuras 1-14. Mimosa dasilvae A. S. Silva \& R. Secco, sp. nov. I. Ramo com inflorescência. 2. Par de foliólulos. 3. Detalhe da base do foliólulo, mostrando os tricomas. 4. Cálice setoso. 5. Capítulo com flores abertas. 6. Flor, mostrando o tubo da corola glabro e os lobos setosos. 7. Ovário com estilete lateral. 8. Brácteas. 9. Bractéolas. 10. Botão floral. 11. Botão floral seccionado mostrando os estames. 12. Estame em vista ventral. 13. Estame em vista dorsal. 14. Capítulo na pré-antese (J. B. Silva 50I). 
colega Antônio Eliélson Rocha, bolsista do $\mathrm{PCI} / \mathrm{CNPq}-\mathrm{MPEG}$, pela ilustração da espécie; ao Dr. José Maria Albuquerque, professor aposentado da Faculdade de Ciências Agrárias do Pará, pela versão da diagnose latina da espécie; aos "referees" pelas sugestões apresentadas.

\section{Bibliografia citada}

Barneby, R.C. 1991, Sensitivae Censitae. A description of the genus Mimosa Linnaeus (Mimosaceae) in the New World. Mem. New York Bot, Gard. 65: 1-835.

Lewis, G.P.; Elias, T. S. 1981. Tribe Mimoseae. In: R. M. Polhill; P. H. Raven (eds.) Advances in Legume Systematics 1: 155-168. Royal Botanic Gardens, Kew. 